\title{
Molecular Epidemiological Survey of Theileria orientalis in Thua Thien Hue Province, Vietnam
}

\author{
Altangerel KHUKHUU' ${ }^{1}$, Dinh Thi Bich $\mathrm{LAN}^{2}$, Phung Thang $\mathrm{LONG}^{3)}$, Akio UENO ${ }^{1)}$, Yan $\mathrm{LI}^{1)}$, Yuzi LUO ${ }^{1)}$, \\ Alan Caine Costa de MACEDO $^{1)}$, Kotaro MATSUMOTO ${ }^{4)}$, Hisashi INOKUMA ${ }^{4}$, Shin-Ichiro KAWAZU ${ }^{1)}$, \\ Ikuo IGARASHI ${ }^{1)}$, Xuenan XUAN ${ }^{1)}$ and Naoaki YOKOYAMA ${ }^{1) *}$ \\ ${ }^{1)}$ National Research Center for Protozoan Diseases and ${ }^{4)}$ Department of Clinical Veterinary Science, Obihiro University of Agriculture \\ and Veterinary Medicine, Obihiro, Hokkaido 080-8555, Japan, ${ }^{2}$ Institute of Resources Environment and Biotechnology, Hue University, \\ Hue and ${ }^{3}$ Hue University of Agriculture and Forestry, Hue, Vietnam
}

(Received 23 October 2010/Accepted 11 December 2010/Published online in J-STAGE 24 December 2010)

ABSTRACT. Theileria orientalis is a benign bovine protozoan parasite that occasionally causes serious economic loss in the livestock industry. We report the findings of a molecular epidemiological survey of T. orientalis in 94 Vietnamese yellow cattle, 43 water buffaloes, 21 sheep, 21 goats and 85 blood-sucking ticks of cattle in the Thua Thien Hue province of Vietnam. The major piroplasm surface protein (MPSP) gene of $T$. orientalis was detected using polymerase chain reaction from 13 cattle (13.8\%), 11 water buffaloes $(25.6 \%), 1$ sheep $(4.8 \%)$ and 9 ticks (10.6\%). Phylogenetic analysis using MPSP gene sequences showed the presence of seven genotypes, four previously categorized genotypes (Types 1, 3, 5 and 7) and three new genotypes (Types N-1, N-2 and N-3). KEY WORDS: cattle, genotype, MPSP, Theileria orientalis, Vietnam.

J.Vet.Med.Sci.73(5): 701-705, 2011

Theileria orientalis is a tick-transmitted, intraerythrocytic protozoa belonging to the phylum Apicomplexa, and a member of the benign Theileria group (Theileria sergenti/ buffeli/orientalis) [19]. T. orientalis or related species are widely distributed in many Asia-Pacific countries, including Japan [11, 20], Korea [7, 13], China [14], Taiwan [12], Thailand [8, 16], Cambodia [4], Vietnam [9], Indonesia [2] and Australia [6]. Generally, the pathogenicity of $T$. orientalis is lower than that for T. parva and T. annulata, however can occasionally cause symptoms including fever, anemia, and anorexia in infected cattle [18]. Serious economic losses in the livestock industry can subsequently arise.

Major piroplasm surface protein (MPSP) of $T$. orientalis is expressed as an immunodominant protein on the parasite surface during the intraerythrocytic stage (piroplasm) [5, 10]. This coding gene exhibits significant sequence diversity among field isolates of $T$. orientalis $[3,8,23]$. Currently, eight genotypes of $T$. orientalis are known worldwide based on registered MPSP gene sequences [15]. Our recent survey carried out in Hokkaido, Kumamoto, and Okinawa prefectures of Japan revealed at least five genotypes of $T$. orientalis (Types 1, 2, 3, 4 and 5) in Japan [15, $22]$. Thus, the MPSP gene may be a reliable molecular marker for studies on the epidemiology of $T$. orientalis.

Although a worldwide distribution of this parasite has been reported, there is insufficient data regarding the sequence identification and genotyping of $T$. orientalis, especially using the MPSP gene. In the present study, we conducted a molecular epidemiological survey of $T$. orien-

\footnotetext{
* Correspondence to: Yokoyama, N., National Research Center for Protozoan Diseases, Obihiro University of Agriculture and Veterinary Medicine, Inada-cho, Obihiro, Hokkaido 080-8555, Japan.

e-mail: yokoyama@obihiro.ac.jp
}

talis in domestic animals of the Thua Thien Hue province of Vietnam during 2010 (Fig. 1A). Vietnam is located within Southeast Asia and exhibits high temperatures and humidity throughout the year. The present field survey was carried out in February after a long rainy season (Temperature: 22 $27^{\circ} \mathrm{C}$ ). Blood samples from Vietnamese yellow cattle (Bos taurus; Fig. 1B), water buffaloes (Bubalus arnee; Fig. 1C), sheep (Ovis aries) and goats (Capra aegagrus hircus) were randomly collected from 13, 6, 1 and 1 farm/s, respectively, as shown in Table 1. Furthermore, half-engorged ticks (nymphs or adults) were collected from the skin of randomly selected Vietnamese yellow cattle (1-3 ticks per animal) and then fixed in acetone. All of the collected ticks were morphologically identified as Rhipicephalus (Boophilus) microplus (data not shown). Individual families typically managed each dairy farm, whereby farmers owned 10 15 domestic animals and had occasionally exchanged animals with neighboring farms. Although field veterinarians in the province had often detected Theileria infection of domestic animals through classical blood microscopic observation, species identification of the parasites had not been performed.

Genomic DNA was extracted from $100 \mu l$ of whole blood using a QIAamp® DNA Blood Mini Kit (Qiagen, Hilden, Germany) and from acetone-fixed ticks using a commercial kit (Isohair, Nippon Gene Co., Tokyo, Japan), according to the manufacturer's instructions. The resulting $200 \mu \mathrm{l}$ eluted DNA samples (approximately $6 \mu \mathrm{g} / \mu l$ ) were stored at $-30^{\circ} \mathrm{C}$ for subsequent PCR analyses. PCR amplification, DNA sequencing and phylogenetic analysis were based on the MPSP gene of $T$. orientalis according to previous reports $[15,22]$. Pairwise comparisons of the MPSP gene sequences were conducted using the EMBOSS needle program (European Molecular Biology Laboratory) to deter- 

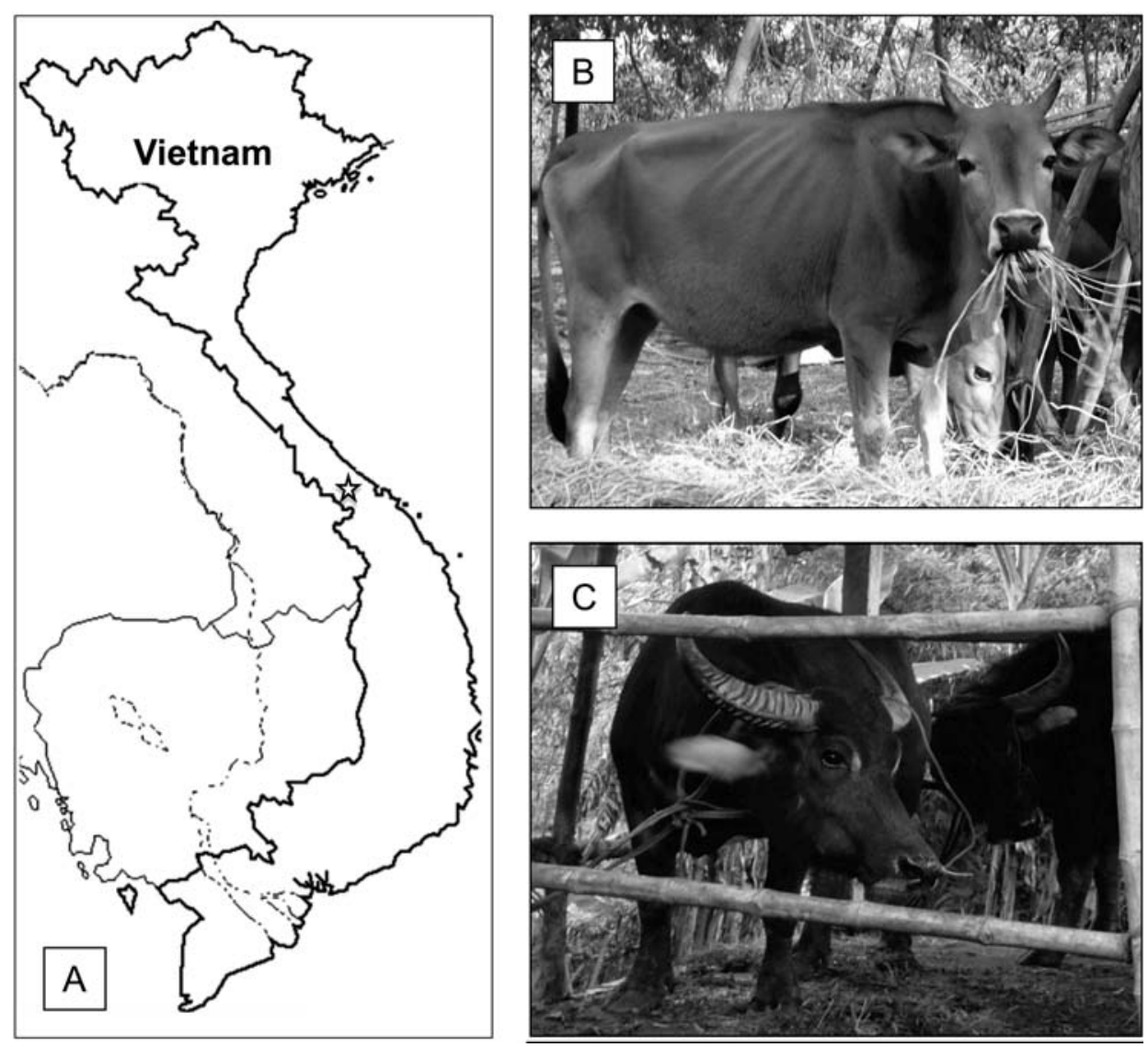

Fig. 1. Geographical map of Vietnam (A) and images of Vietnamese yellow cattle (B) and water buffalo (C). Star indicates the location of Thua Thien Hue Province, where blood and tick samples were collected.

Table 1. MPSP-PCR diagnosis and genotyping of T. orientalis from animal and tick samples collected in the Thua Thien Hue province of Vietnam, February 2010

\begin{tabular}{cccc}
\hline Species & $\begin{array}{c}\text { Total number of } \\
\text { collected samples }\end{array}$ & $\begin{array}{c}\text { Number of positive } \\
\text { samples (\%) }\end{array}$ & $\begin{array}{c}\text { Isolated Genotypes } \\
(\text { Number })^{\mathrm{a})}\end{array}$ \\
\hline Cattle & 94 & $13(13.8)$ & $1(1), 3(5), 5(5), 7(1), \mathrm{N}-3(1)^{\mathrm{b})}$ \\
Water buffalo & 43 & $11(25.6)$ & $5(1), \mathrm{N}-2^{\mathrm{b})}(4)$ \\
Sheep & 21 & $1(4.8)$ & $\mathrm{N}-1^{\mathrm{b}}(1)$ \\
Goat & 21 & $0(0.0)$ & $5(5), 7(1)$ \\
Tick $^{\mathrm{c})}$ & 85 & $9(10.6)$ & \\
\hline
\end{tabular}

a) Refers to Fig. 3 .

b) New genotypes detected in the present study.

c) Collected from cattle.

mine percentage homology among all $T$. orientalis genotypes.

Using the diagnostic MPSP-PCR assay, the MPSP gene was positively detected in $13(13.8 \%)$ cattle, $11(25.6 \%)$ water buffaloes, $1(4.8 \%)$ sheep and $9(10.6 \%)$ ticks (Table 1). Some farms were positive and others were negative in the diagnosis. Specific DNA amplification in the ticks was possibly derived from the blood meals consumed from infected cattle. Although Rhipicephalus (Boophilus) microplus is not reported as a vector for $T$. orientalis, none of the common vectors, Haemaphysalis spp., Amblyomma spp. and Dermacentor spp. [17, 19, 21], were detected in the present study. Although our study did not detect the parasite in goats (Table 1), there have been previous reports on $T$. orientalis infection in other ruminants, such as wild deer and antelopes [19]. Therefore, a large-scale epidemiological survey would be especially beneficial for sheep and goat populations. 


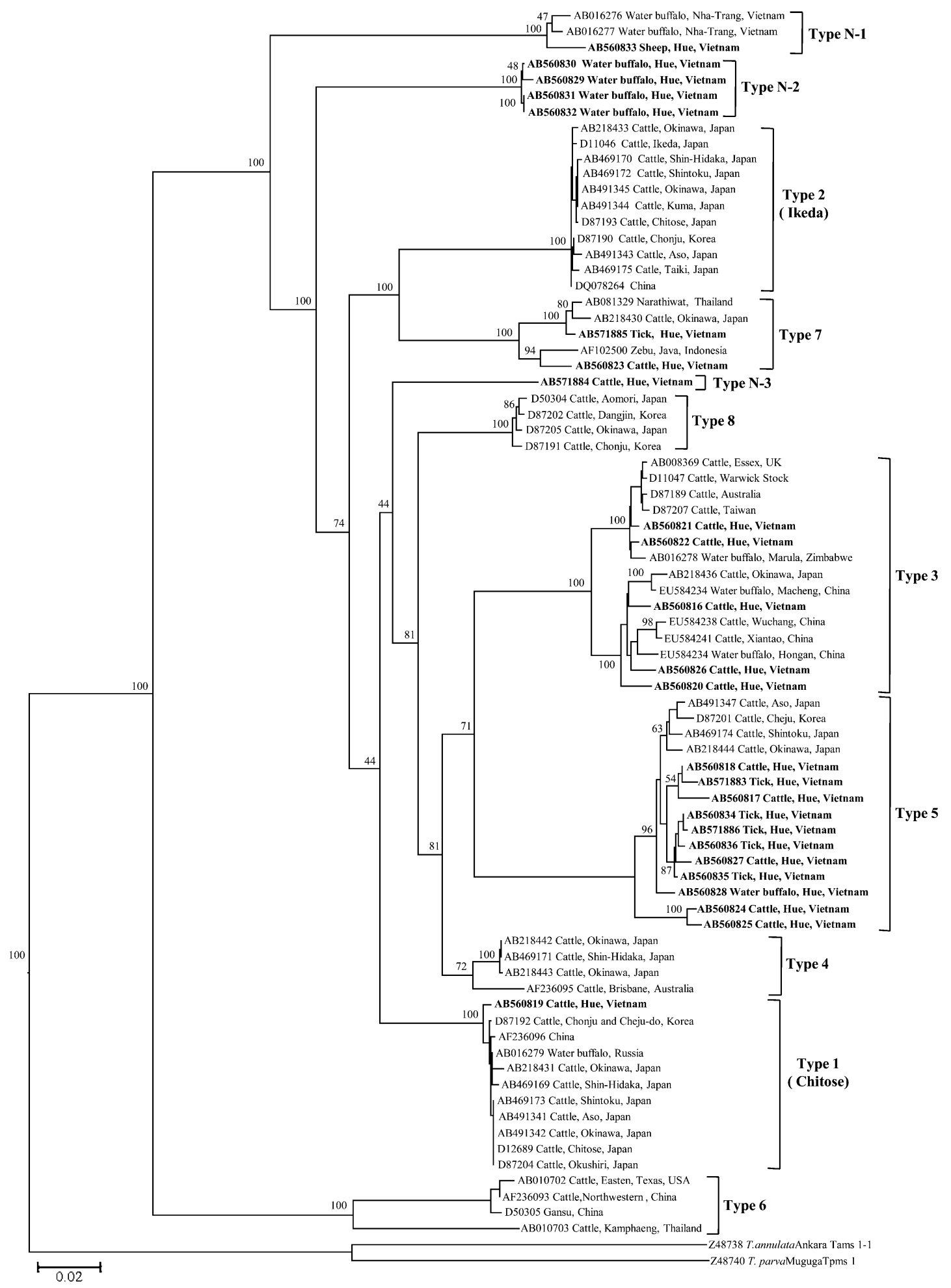

Fig. 2. Phylogenetic tree of the MPSP gene sequences derived from the blood and tick samples collected from domestic animals in the Thua Thien Hue province of Vietnam, together with previously registered sequences from the GenBank database. MPSP gene sequences determined in the present study are shown in bold-faced type and refer to the GenBank accession numbers as indicated at the end of each branch. Numbers shown at branch nodes indicate bootstrap values. Recently, a group of type 6 was classified as T. sinensis [14]. 


\begin{tabular}{|c|c|c|c|c|c|c|c|c|c|c|c|c|c|c|c|c|c|c|}
\hline \multirow{2}{*}{$\begin{array}{l}\text { Group } \\
\text { Type }\end{array}$} & \multicolumn{3}{|c|}{ Ikeda group } & \multicolumn{9}{|c|}{ Chitose group } & \multicolumn{2}{|c|}{ Buffalo 1} & \multicolumn{2}{|c|}{ Buffalo 2} & \multirow{2}{*}{ 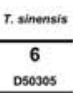 } & \multirow{2}{*}{$\begin{array}{c}\text { r. annulata } \\
\mathrm{Ta} \\
248738 \\
\end{array}$} \\
\hline & $\begin{array}{c}2 \\
011046 \\
\end{array}$ & $\begin{array}{c}7 \\
\text { ABs719s5 } \\
\end{array}$ & $\begin{array}{c}7 \\
\text { ABseob23 } \\
\end{array}$ & $\begin{array}{c}3 \\
\text { ABseos } 21 \\
\end{array}$ & $\begin{array}{c}3 \\
\text { ABscos } 26 \\
\end{array}$ & $\begin{array}{c}5 \\
\text { ABS60818 } \\
\end{array}$ & $\begin{array}{c}5 \\
\text { ABseob } 24 \\
\end{array}$ & $\begin{array}{c}4 \\
\text { AB469171 } \\
\end{array}$ & $\begin{array}{c}8 \\
050304 \\
\end{array}$ & $\begin{array}{c}\mathrm{N}-3 \\
\text { AB571884 }\end{array}$ & $\begin{array}{c}1 \\
\text { ABseos } 19 \\
\end{array}$ & $\begin{array}{c}1 \\
012699 \\
\end{array}$ & $\begin{array}{c}\mathrm{N}-2 \\
\text { ABse0830 }\end{array}$ & $\begin{array}{c}\mathrm{N}-2 \\
\text { ABse0331 } \\
\end{array}$ & $\begin{array}{c}\mathrm{N}-1 \\
\text { ABO16276 }\end{array}$ & $\begin{array}{c}\mathrm{N}-1 \\
\text { ABs60033 }\end{array}$ & & \\
\hline D11046 & 100.0 & 88.8 & 88.6 & 66.0 & 65.5 & 64.1 & 64.3 & 68.7 & 84.0 & 68.8 & 69.0 & 87.5 & 66.5 & 66.6 & 80.2 & 63.3 & 67.2 & 57.2 \\
\hline AB571885 & & 100.0 & 96.6 & 83.9 & 84.0 & 82.3 & 82.6 & 87.0 & 82.6 & 85.1 & 88.5 & 88.3 & 83.5 & 83.6 & 81.1 & 81.4 & 74.6 & 61.2 \\
\hline AB560823 & & & 100.0 & 84.5 & 83.1 & 82.6 & 82.7 & 86.9 & 82.9 & 84.3 & 88.3 & 88.2 & 83.3 & 83.4 & 81.1 & 81.5 & 74.6 & 61.9 \\
\hline AB560821 & & & & 100.0 & 96.3 & 86.8 & 87.1 & 92.1 & 85.6 & 87.0 & 87.8 & 87.6 & 83.7 & 83.5 & 79.5 & 78.9 & 60.3 & 60.3 \\
\hline AB560826 & & & & & 100.0 & 86.7 & 87.4 & 91.6 & 84.7 & 86.0 & 87.3 & 87.0 & 83.2 & 83.1 & 79.1 & 77.7 & 72.2 & 60.0 \\
\hline AB560818 & & & & & & 100.0 & 96.8 & 88.7 & 84.5 & 84.8 & 86.6 & 86.5 & 82.6 & 82.4 & 77.7 & 77.0 & 74.8 & 62.0 \\
\hline AB560824 & & & & & & & 100.0 & 88.1 & 83.8 & 84.3 & 85.7 & 85.4 & 81.6 & 81.4 & 77.9 & 77.4 & 74.6 & 60.3 \\
\hline AB469171 & & & & & & & & 100.0 & 90.5 & 91.9 & 92.4 & 92.4 & 88.7 & 88.5 & 81.1 & 80.9 & 74.4 & 61.0 \\
\hline D50304 & & & & & & & & & 100.0 & 87.9 & 88.5 & 88.5 & 82.9 & 82.9 & 77.4 & 77.0 & 72.4 & 60.0 \\
\hline AB571884 & & & & & & & & & & 100.0 & 91.4 & 91.1 & 86.7 & 86.9 & 80.1 & 80.4 & 73.8 & 61.5 \\
\hline AB560819 & & & & & & & & & & & 100.0 & 99.4 & 87.2 & 87.4 & 82.5 & 82.4 & 74.9 & 63.5 \\
\hline D12689 & & & & & & & & & & & & 100.0 & 87.2 & 87.4 & 82.4 & 82.3 & 74.7 & 63.0 \\
\hline AB560830 & & & & & & & & & & & & & 100.0 & 99.9 & 81.8 & 82.0 & 74.8 & 63.0 \\
\hline AB560831 & & & & & & & & & & & & & & 100.0 & 81.8 & 82.0 & 74.9 & 62.9 \\
\hline AB016276 & & & & & & & & & & & & & & & 100.0 & 98.2 & 72.6 & 62.5 \\
\hline AB560833 & & & & & & & & & & & & & & & & 100.0 & 72.3 & 62.1 \\
\hline D50305 & & & & & & & & & & & & & & & & & 100.0 & 60.8 \\
\hline Z48738 & & & & & & & & & & & & & & & & & & 100.0 \\
\hline
\end{tabular}

Fig. 3. Pairwise comparisons of the representative MPSP gene sequences categorized in each genotype. Comparisons were conducted using the EMBOSS needle program to determine the percentage homology between all T. orientalis genotypes. Acc. indicates GenBank accession numbers, and a T. annulata sequence was used as an outgroup species.

MPSP genes from field isolates were successfully cloned into a TA-cloning plasmid vector using 13, 5, 1 and 6 PCR fragment/s derived from the cattle, water buffaloes, sheep and tick samples, respectively. Inserts were sequenced and used for subsequent phylogenetic and pairwise comparative analyses (Figs. 2 and 3, respectively). Only two DNA sequences derived from the water buffaloes were identical (GenBank accession numbers, AB560831 and AB560832), while intra-sequence variation was observed among the remaining DNA sequences. Phylogenetic analysis using MPSP gene sequences revealed four genotypes (Types 1, 3, 5 and 7), which had been previously categorized, from cattle, water buffalo or tick samples (Table 1 and Fig. 2). Additionally, three new genotypes (Types N-1, N-2 and N-3) were found in the sheep, water buffalo and cattle samples, respectively. While type $\mathrm{N}-2$ detected in the water buffaloes was obviously separated on the phylogenetic tree (Fig. 2), type $\mathrm{N}-1$ detected in the sheep formed a unique cluster with T. buffeli gene sequences previously isolated from the water buffaloes in Vietnam [3,9]. N-1 and N-2 types are potentially genotypes specific to water buffalo in Vietnam. Five genotypes (Types 1, 3, 5, 7 and N-3) of T. orientalis were identified in the cattle, whereas only two genotypes (Types 5 and N-2) were detected from the water buffaloes (Table 1). Additionally, two genotypes (Types 5 and 7) of $T$. orientalis were detected in Rhipicephalus tick samples (Table 1). Types 2, 4 and 8 of $T$. orientalis were not detected in Vietnam. The finding in which the two genotypes from individual tick sample matched genotypes from the host cattle supports the assumption that PCR amplification in the tick samples may be due to the blood meal as described above.

Based on the phylogenetic findings, it is concluded that $T$. orientalis population in the cattle can be divided into the "Ikeda group" consisting of types 2 (Ikeda type) and 7 (88.6-96.6\% homology in Fig. 3), and the "Chitose group" consisting of types 1 (Chitose type), 3, 4, 5, 8 and N-3 (83.8-99.4\% homology). Certain genotypes (at least types 1,3 and 5 ) in the Chitose group are potentially transmitted between cattle and water buffaloes. Types N-1 and N-2 may form separate groups ("Buffalo groups") consisting of Theileria populations distributed in water buffaloes and other ruminant(s) [1]. Types N-1 and N-2 showed low genetic homology to each other $(81.8-82.0 \%)$, and to the other genotypes (66.5-88.5\%) (Fig. 3). Further study is required to determine whether the parasites of Buffalo groups are also detected in cattle. Type 6 was previously found in the cattle and yaks, and recently classified as Theileria sinensis [14]. This genotype was distinguishable from the other T. orientalis groups in our study (60.3-74.9\% homology, Fig. 3). Further elucidation is necessary on the relationship of $T$. orientalis which was first identified in sheep in our study to that in the water buffaloes.

Our results indicate that at least seven genotypes of $T$. orientalis currently exist in Vietnam. Further large-scale epidemiology would be useful in better understanding the geographical distributions, host specificities and clinical pathologies of the different genotypes of $T$. orientalis, and their relationships with the tick populations.

ACKNOWLEDGMENTS. We thank all the staff of the farms and veterinary hospitals in Vietnam who participated 
in this study for their kind cooperation. In addition, we thank Ms. Hiroko Yamamoto for her excellent technical assistance. This study was supported by a program for the Promotion of Basic Research Activities for Innovative Biosciences (PROBRAIN), a grant from the Global COE Program from the Japanese Ministry of Education, Science, Sports, Culture and Technology, and Grants-in-Aid for Scientific Research from the Japan Society for Promotion of Science (JSPS), Japan.

\section{REFERENCES}

1. Fujisaki, K., Kawazu, S. and Kamio, T. 1994. The taxonomy of the bovine Theileria spp. Parasitol. Today 10: 31-33.

2. Govaerts, M., Verhaert, P., Jongejan, F. and Goddeeris, B. M. 2002. Characterisation of the $33 \mathrm{kDa}$ piroplasm surface antigen of Theileria orientalis/sergenti/buffeli isolates from West Java, Indonesia. Vet. Parasitol. 104: 103-117.

3. Gubbels, M. J., Hong, Y., van der Weide, M., Qi, B., Nijman, I. J., Guangyuan, L. and Jongejan, F. 2000. Molecular characterisation of the Theileria buffeli/orientalis group. Int. J. Parasitol. 30: 943-952.

4. Inoue, M., Van Nguyen, D., Meas, S., Ohashi, K., Sen, S., Sugimoto, C. and Onuma, M. 2001. Survey of Theileria parasite infection in cattle in Cambodia and Vietnam using piroplasm surface protein gene-specific polymerase chain reaction. J. Vet. Med. Sci. 63: 1155-1157.

5. Iwasaki, T., Kakuda, T., Sako, Y., Sugimoto, C. and Onuma, M. 1998. Differentiation and quantification of Theileria sergenti piroplasm types using type-specific monoclonal antibodies. J. Vet. Med. Sci. 60: 665-669.

6. Izzo, M. M., Poe, I., Horadagoda, N., De Vos, A. J. and House, J. K. 2010. Haemolytic anaemia in cattle in NSW associated with Theileria infections. Aust. Vet. J. 88: 45-51.

7. Jeong, W., Yoon, S. H., An, D. J., Cho, S. H., Lee, K. K. and Kim, J. Y. 2010. A molecular phylogeny of the benign Theileria parasites based on major piroplasm surface protein (MPSP) gene sequences. Parasitology 137: 241-249.

8. Kakuda, T., Shiki, M., Kubota, S., Sugimoto, C., Brown, W. C., Kosum, C., Nopporn, S. and Onuma, M. 1998. Phylogeny of benign Theileria species from cattle in Thailand, China and the U.S.A. based on the major piroplasm surface protein and small subunit ribosomal RNA genes. Int. J. Parasitol. 28: 1261-1267.

9. Kawazu, S., Kamio, T., Kakuda, T., Terada, Y., Sugimoto, C. and Fujisaki, K. 1999. Phylogenetic relationships of the benign Theileria species in cattle and Asian buffalo based on the major piroplasm surface protein (p33/34) gene sequences. Int. J. Parasitol. 29: 613-618.

10. Kawazu, S., Sugimoto, C., Kamio, T. and Fujisaki, K. 1992. Analysis of the genes encoding immunodominant piroplasm surface proteins of Theileria sergenti and Theileria buffeli by nucleotide sequencing and polymerase chain reaction. Mol. Biochem. Parasitol. 56: 169-175.

11. Kim, J. Y., Yokoyama, N., Kumar, S., Inoue, N., Yamaguchi, T., Sentoku, S., Fujisaki, K. and Sugimoto, C. 2004. Molecular epidemiological survey of benign Theileria parasites of cattle in Japan: detection of a new type of major piroplasm surface protein gene. J. Vet. Med. Sci. 66: 251-256.

12. Kim, S. J., Tsuji, M., Kubota, S., Wei, Q., Lee, J. M., Ishihara, C. and Onuma, M. 1998. Sequence analysis of the major piroplasm surface protein gene of benign bovine Theileria parasites in east Asia. Int. J. Parasitol. 28: 1219-1227.

13. Ko, M. S., Lee, K. K., Hwang, K. K., Kim, B. S., Choi, G. C. and Yun, Y. M. 2008. Antigenic diversity of Theileria major piroplasm surface protein gene in Jeju black cattle. J. Vet. Sci. 9: $155-160$.

14. Liu, A., Guan, G., Liu, Z., Liu, J., Leblanc, N., Li, Y., Gao, J., Ma, M., Niu, Q., Ren, Q., Bai, Q., Yin, H. and Luo, J. 2010. Detecting and differentiating Theileria sergenti and Theileria sinensis in cattle and yaks by PCR based on major piroplasm surface protein (MPSP). Exp. Parasitol. 126: 476-481.

15. Ota, N., Mizuno, D., Kuboki, N., Igarashi, I., Nakamura, Y., Yamashina, H., Hanzaike, T., Fujii, K., Onoe, S., Hata, H., Kondo, S., Matsui, S., Koga, M., Matsumoto, K., Inokuma, H. and Yokoyama, N. 2009. Epidemiological survey of Theileria orientalis infection in grazing cattle in the eastern part of Hokkaido, Japan. J. Vet. Med. Sci. 71: 937-944.

16. Sarataphan, N., Kakuda, T., Chansiri, K. and Onuma, M. 2003. Survey of benign Theileria parasites of cattle and buffaloes in Thailand using allele-specific polymerase chain reaction of major piroplasm surface protein gene. J. Vet. Med. Sci. 65 : 133-135.

17. Shimizu, S., Nojiri, K., Matsunaga, N., Yamane, I. and Minami, T. 2000. Reduction in tick numbers (Haemaphysalis longicornis), mortality and incidence of Theileria sergenti infection in field-grazed calves treated with flumethrin pouron. Vet. Parasitol. 92: 129-138.

18. Shiono, H., Yagi, Y., Thongnoon, P., Kurabayashi, N., Chikayama, Y., Miyazaki, S. and Nakamura, I. 2001. Acquired methemoglobinemia in anemic cattle infected with Theileria sergenti. Vet. Parasitol. 102: 45-51.

19. Sugimoto, C. and Fujisaki, K. 2002. Non-transforming Theileria parasites of ruminants. pp. 93-106. In: Theileria (Black, S. J. and Seed, J. R. eds.), Kluwer Academic Publishers, U.S.A.

20. Yamaguchi, T., Yamanaka, M., Ikehara, S., Kida, K., Kuboki, N., Mizuno, D., Yokoyama, N., Narimatsu, H. and Ikehara, Y. 2010. Generation of IFN-gamma-producing cells that recognize the major piroplasm surface protein in Theileria orientalis-infected bovines. Vet. Parasitol. 171: 207-215.

21. Yin, H., Guan, G., Ma, M., Luo, J., Lu, B., Yuan, G., Bai, Q., Lu, C., Yuan, Z. and Preston, P. 2002. Haemaphysalis qinghaiensis ticks transmit at least two different Theileria species: one is infective to yaks, one is infective to sheep. Vet. Parasitol. 107: 29-35.

22. Yokoyama, N., Ueno, A., Mizuno, D., Kuboki, N., Khukhuu, A., Igarashi, I., Miyahara, T., Shiraishi, T., Kudo, R., Oshiro, M., Zakimi, S., Sugimoto, C., Matsumoto, K. and Inokuma, H. Genotypic diversity of Theileria orientalis detected from cattle grazing in Kumamoto and Okinawa prefectures of Japan. $J$. Vet. Med. Sci. (in press).

23. Zhuang, W., Sugimoto, C., Matsuba, T., Niinuma, S., Murata, M. and Onuma, M. 1994. Analyses of antigenic and genetic diversities of Theileria sergenti piroplasm surface proteins. $J$. Vet. Med. Sci. 56: 469-473. 